\title{
OCYPUS CURTIPENNIS MOTSCHULSKY, 1849 (COLEOPTERA, STAPHYLINIDAE, STAPHYLININAE) - SPECIE NOUĂ ÎN FAUNA REPUBLICII MOLDOVA
}

\author{
Mihailov Irina \\ Institutul de Zoologie, MECC, Chișinău, Republica Moldova \\ irinus1982@yahoo.com
}

https://doi.org/10.53937/9789975315975.50

\begin{abstract}
In the general list of rove beetles (Coleoptera, Staphylinidae) are included more than 300 species of Staphylinides present on the Republic of Moldova territory and in the present paper is presented the results obtained and accumulated in time for Ocypus curtipennis Motschulsky, 1849: the collection point, identification proofs, confirmation and storage in the basic collection, taxonomic classification, data related to origin and spread, aspects of bioecology, morphological elements. This species was found in 2010, being identified as a new species for our country's fauna.
\end{abstract}

Key words: Ocypus curtipennis Motschulsky, 1849, Zabriceni village, Edinet District, oak, ashand mapleforest, the collection of Entomology Department.

\section{INTRODUCERE}

În familia Staphylinidae, reprezentanții acestui grupexistenți pe teritoriul țării și studiați insistent după programul de activitate, se regăsesc în număr de peste 300 de specii. Astfel, lista fiind deschisă pentru ulterioare realizări și completări științifice, menționez că după un proces îndelungat de lucruprin identificarecu încercări de preparare și confirmare, specia Ocypus curtipennis Motschulsky, 1849, discuția de bază a lucrării,este rezultatul premieră pentru fauna țării noastre.

Fiind reprezentantul subfam. Staphylininae, în lista celor opt specii din genul Ocypus Sam. cunoscute deja: 1) O. brunnipes F., 2) O. fulvipennis E., 3) O. kuntzeni G.Mull., 4) O. nitens Sch., 5) O. olens O.Mull., 6) O. picipennis F., 7) O. tenebricosus Grav., 8) O. ophtalmicus S. este următorul la număr, cu totalul completat de nouă specii pentru fauna Republicii Moldova. 


\section{MATERIALE ȘI METODE}

În teren: lucrările de acumulare a speciilor din genul Ocypus Leach, 1819 pe parcursul anilor 2010 și 2013 au constat în: • colectări, fixări și etichetări din probele (capcane de sol tip Barber) amplasate înpădurea de stejar cu amestec de frasin și arțar din s. Zăbriceni, r-I Edineț. O dată la 10 zile, probele erau verificate și recompletate cu soluția de capturare. Materialul din probe se colecta încutii de plastic și/sau pachete de polietilenă, cu înscrierea etichetelor.

Înlaborator: •trierea materialului biologic capturat, preparare și clasificare, stocare; •identificarea după caracterele specifice de determinare [3]; • clasificarea și nomenclatura taxonomică a speciei identificate s-a bazat pe sistemul acceptat pe WEB-siturile Fauna Europea [4] și Bio Lib.cz [2]; •analiza datelor: compararea speciei Ocypus curtipennis Motschulsky, 1849 cu speciile din genul Ocypus Leach, 1819. Verificarea și confirmarea a fost efectuată de către entomologul Alexei Solodovnikov, (Universitateadin Copenhaga, Danemarca).

\section{REZULTATE ȘI DISCUŢII}

Colectarea: Conform programelor anuale de activitate științifică, în 2010 și 2013 au fost realizate cercetări în zona de nord a țării, în aceeași pădure de stejar în amestec de frasin și arțar din s. Zăbriceni, r-I Edineț (fig. 1.D). Specia a fost colectată la capcana de sol tip Barber prin extrageri repetate a probelor în recipiente dezinfectate și uscate.

Identificarea, repartizarea: Inițial, după caracterele morfologice, destul de asemănătoare cu reprezentanții din genul Ocypus, stafilininul respectiv a fost tratat și menținut timp de 7 ani ca exemplar al speciei Ocypus tenebricosus Grav. După revizuiri mai aprofundate prin extragerea și analizarea detaliată al organului copulator (aedeagusului) s-a observat o diferență semnificativă care a continuat cu studii intense [3] și confirmări din partea entomologului Solodovnikov Alexei (fig.1.A-B). 
Astfel a fost respinsă prima constatare, stabilindu-se Ocypus curtipennis Motschulsky, 1849, repartizată ca specie separată în colecția Muzeului laboratorului de Entomologie, în cutia nr. 38 (fig.1.C).

Apartenența taxonomică: încrengătura Arthropoda, clasa Insecta, subclasa Pterygota, diviziunea Holometabola, supraordinul Coleopteroidea, ordinul Coleoptera, familia Staphylinidae, subfamilia Staphylininae Latreille, 1802, trib Staphylinini Latreille, 1802, Subtrib Staphylinina Latreille, 1802, genul Ocypus Leach, 1819, specia Ocypus curtipennis Motschulsky, 1849 (sinonime:=gridellii G. Muel.; integer Abeille; kyproticus Coif.; libanoticus G. Muel.; pseudolens Coif.) [2; 4].

Originea și răspândirea: este specie de origine palearctică. Condițiile climaterice sunt favorabile în răspândirea și dezvoltarea acestei specii în Crimeea [5], Bulgaria, Franța [3], Turcia (Bursa, Istanbul, Izmir) [1; 3], Cipru, Siria, Iran, Irac, Rusia [6]. În cazul Republicii Moldova, găsită în zona de nord (2010 și urmărită în 2013), investigaţiile insectei nu sunt finalizate, cercetarea va continua și în alte zone ale țării.

Trăsături morfologice: Adultul este de culoare neagră, foarte asemănător cu stafilinidul Ocypus olens Mull. Prezintă dimensiunea 23-30 mm în lungime. Corpul de culoare negru strălucitor, este străbătut de puncte, dese, bine definite în adîncime. Posedă mandibule dezvoltate și îngroșate [3].

Aspecte din bioecologie: reieșind din specializarea trofică, adultul și larvele sunt prădători, pot consuma diverse specii de insecte și meIci. După preferințele ecologice de populare a diverselor biotopuri și comportarea biologică, adulții pot fi întîlniți în litieră, stratul superficial al solului, în special sub pietre (fiind atrași de umezeală). Se încadrează și în clasa criptobionților, cu statutul de specie nidicolă (conviețuind cu popândăii de câmp, cârtiţele, șoarecii de câmp și șoarecii de casă). Perioada sezonieră activă este martie-octombrie. Hibernează adultul și larva (inițial pregătindu-și un "cuib" specific de protecție pentru această perioadă) [5]. 


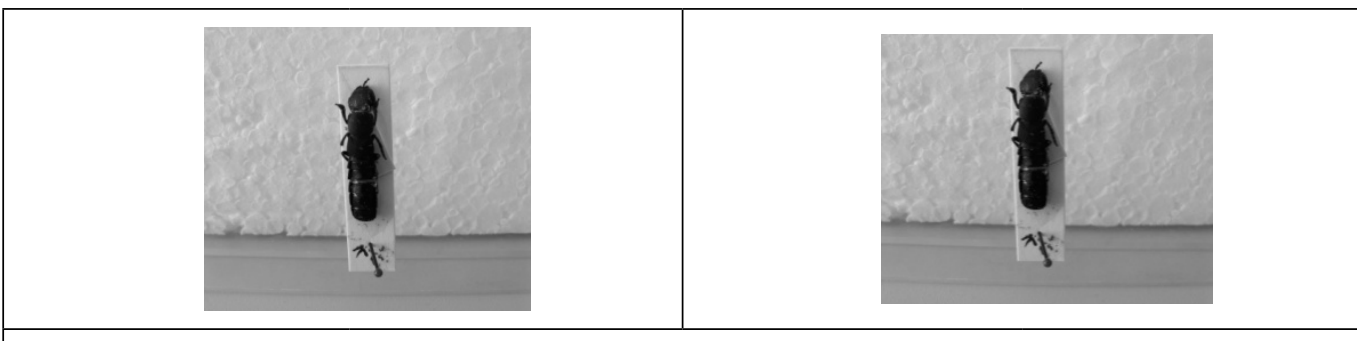

(A) Imago privit dorsal

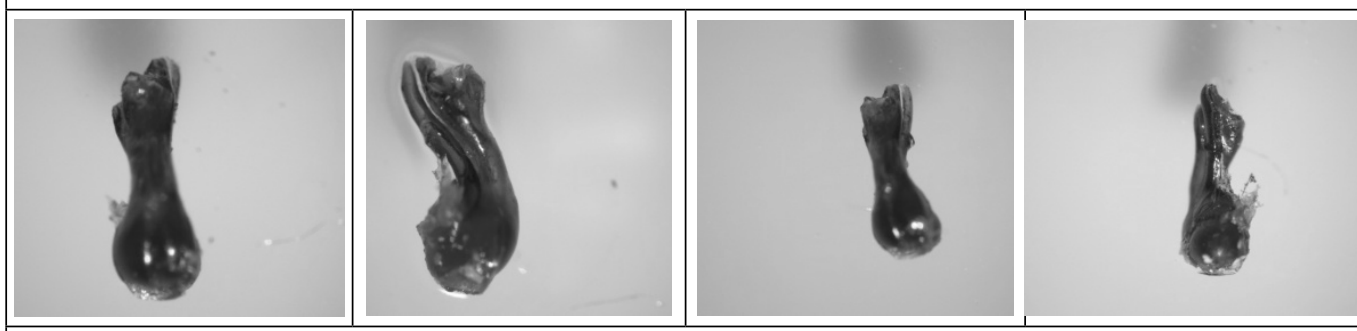

(B) Aedeagusul privit din mai multe poziții

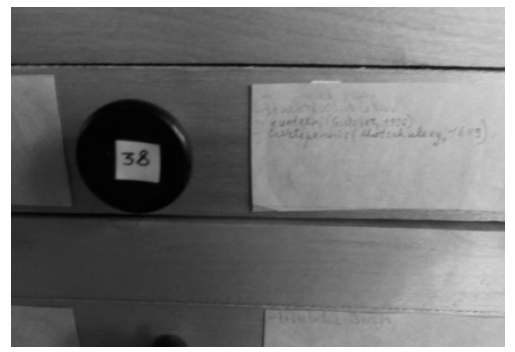

(C) Stocarea speciei în colecția laboratorului de Entomologie, Coleoptera, Staphylinidae (nr.38)
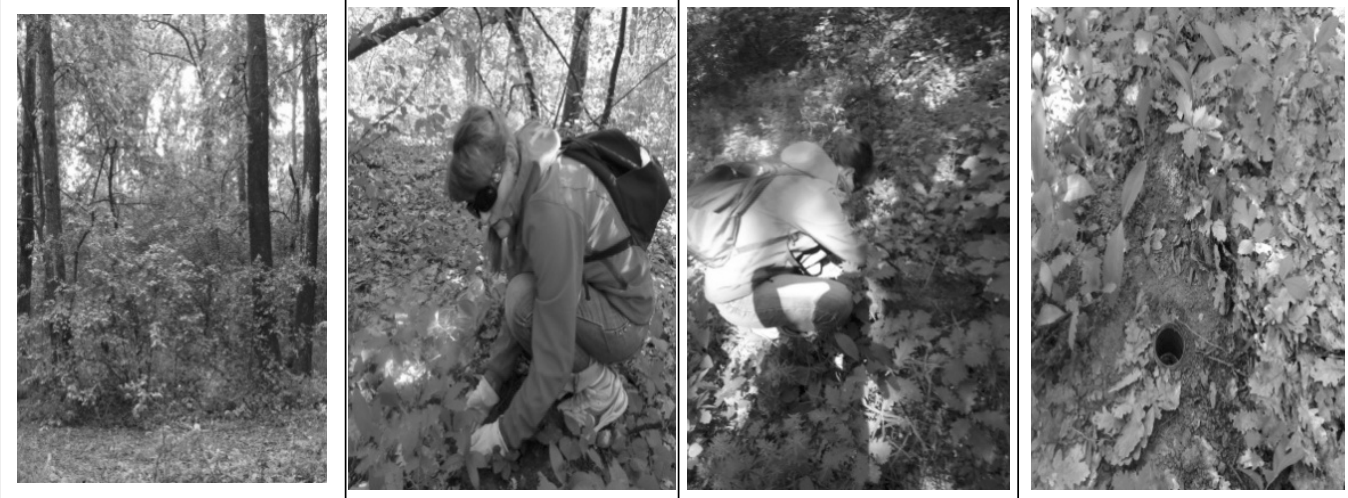

(D) colectări în s. Zăbriceni, r-I Edineț: pădure de stejar cu frasin și arțar $(2010,2013)$

Figura 1. Stafilinul Ocypus curtipennis Motschulsky, 1849, specie nouă pentru fauna Republicii Moldova, Muzeul laboratorului de Entomologie, IZ, (foto: Mihailov Irina) 


\section{CONCLUZII}

Specia Ocypus curtipennis Motschulsky, 1849, prezentînd noutate faunistică pentru țara noastră, rămîne un subiect deschis pentru continuarea cercetărilor în stabilirea statutului în biodiversitate și alte aspecte referitoare la: inspectare, urmărirea distribuției în alte biotopuri din țară, factorii care pot influiența densitatea numerică a populației, măsurile posibile în aplicarea protecției și menținerii acestei insecte pe teritoriul țării.

Studiile au fost realizate în cadrul proiectului instituțional fundamental 15.817.02.12F.

\section{REFERINȚE BIBLIOGRAFICE}

1. Anlas S. Distributional checklist of the Staphylinidae (Coleoptera) of Turkey, with new and additional records. In: Linzer biologiezentrum Beitr, 41/1, Austria, 2009, p.215-342.

2. Biolib.Cz. Biological Library. http://www.biolib.cz/en/stats/ id84/ (online: 14.01.2017).

3. Coiffait H. Coleoptere Staphylinidae de la region Paleartique occidentale. Sous famille Staphilininae. Tribus Philonthini et Staphylinini.Toulouse, 1974, vol. 2, 1-583 p.

4. Fauna Europeae http://www.faunaeur.org/full/results. phpid/11886. (online: 14.01.2017).

5. Красная книга Украины. In: www.redbook-ua.org/ru/item/ocypus-curtipennis-motschulsky/ Красная книга Украины 2010-2018 (online: 26.03.2018).

6. Шаврин А. Список стафилиния (Staphylinidae) фауны России. www. zin.ru/ animalia/Coleoptera/rus/staph ru.htm. St.-Petersburg, 2006. 532k. (online: 24.01.2018). 